\title{
The Commodity Form of Safety Information
}

\author{
Rodrigo Finkelstein
}

\author{
Simon Fraser University, Vancouver, Canada, rfindels@sfu.ca
}

\begin{abstract}
The production of safety information is deemed a vital resource to protect human lives at the work site. The injury rate, lost days, incapacity rate, and fatality rate, are key indicators to prop up labour risk awareness and identify job hazards. However, safety information gets highly distorted because it does not only measure risk but serves as a means of exchange. It determines the amount of money to be swapped between Workers' Compensation Boards and their client corporations. Moreover, as a depository of exchange value, safety information tends to exert pressure over social reality rather than just being a passive reflection of it. This paper discloses the commodity form of safety information. Based on a political economy of information framework, it identifies, describes, and analyses the safety information commodity in its active role of organizing safety and labour health.
\end{abstract}

Keywords: Political Economy of Information, Health Communication, Workers' Compensation Board, Safety Information, Occupational Health and Safety

Acknowledgement: Thank you to Enda Brophy and Betty Ackah for valuable feedback on this paper and to the reviewers for helpful suggestions. This research was supported by a Student Graduate Stipend Award from the Centre for Research on Work Disability Policy (Social Sciences and Humanities Research Council Award 8952012-1017). I am grateful to John Calvert for nominating me for this award.

\section{Introduction}

Workers' Compensation Boards (WCBs) concentrate the production and circulation of vast informational resources to protect human lives at the work site. These agencies are responsible for collecting, organizing, and circulating numbers, data, images, concepts, and texts through which workers can make sense and respond to labour risks. Among the variety of symbolic resources that WCBs produce and distribute, safety information-i.e. injury rate, lost days, incapacity rate and fatality rate-is regarded as significant since it advises on the risk level, props up awareness among workers, and enables the identification of labour hazards. However, although safety information is deemed a vital resource to protect workers' health, no one has critically examined the process of production through which it is brought into existence. This can be explained mainly because safety information is regarded as a sub-product of WCBs' medical and risk prevention activities. It is understood just as a reflection of those tragic events that take place at the worksite as well as those preventive and medical practices related to them. For example, both the injury rate (number of injuries per 100 workers in a given period) and the lost days (the average of treatment time due to an injury or disease) are regarded as a mimicry/an imitation of reality; the injury rate reflects the number of injuries that workers suffer at the worksite and the lost days reflects the average treatment time that workers undergo before returning to work. Under this perspective, safety information constitutes a passive account of undeniable physical events that take place within the health and safety business. Safety information is just regarded as a reactive description of labour health and safety related events. So why should someone bother himself in examining the production of safety information? The analysis that I am about to present turns this relationship upside down. It suggests that it is not safety information that reflects a given reality but on the contrary, reality that reflects safety information. Although this might sound extremely esoteric, it is very simple and straightforward. Particular and concrete events take place because of the need of WCBs and their client companies to control safety information to their economic advantage. Due to the fact that safety information serves as means of ex- 
change within a business relationship, safety information tends to exert pressure over social reality rather than the other way round. As safety information determines the amount of money to be exchanged between WCBs and corporations, both WCBs and their client companies are economically stimulated to intervene in reality in order to manipulate safety information in their own favour. For example, corporations tend to misinform, discourage and prevent workers from reporting injuries in an effort to halt the rise of the injury rate (Zoller 2003). On their part, private WCBs engage in the practice of "express medical services" to decrease the lost days and protect their client companies from a higher premium to avoid disputes and keep intact their market share (Finkelstein 2009). Therefore, it is not safety information that follows reality but, on the contrary, social reality that goes after safety information. I claim that labour health and safety gets organized by the demand of economic imperatives that safety information poses within a business relationship. The pressure exerted on safety information does not happen because of mysterious forces but by economic ones conjured by the marketplace. It is mainly profit maximization and the logic of competition that draws both WCBs and corporations into questionable practices in order to alter safety information. This phenomenon has been kept in the dark due to an absolute neglect of analysis of the economic significance of safety information. This paper aims to expose and theorize this matter. Following a political economy of information framework on WCBs, I will disclose how safety information is intimately intertwined with WCBs' economic process and strongly tied to an economic regime. Since this examination addresses an economic rationale that is present in WCBs which collect insurance premiums to cover the cost of work-related injuries and diseases, it serves as a blueprint to examine both private and public WCBs. In the lines that follow I will address this matter by describing, analysing, and explaining what I consider to be the key element of this phenomenon: the commodity form of safety information.

\section{Understanding WCBs' Economic Process of Exchange}

WCBs are agencies that manage health and safety at the workplace. They provide medical, prevention and financial resources to deal with work-related injuries, diseases and deaths. A product of the industrial revolution, these agencies aim to prevent and compensate workers' injuries and diseases that happen at work. WCBs appear as a response to the shortcomings of the Workmen's Compensation Act introduced first in Europe and then in North America in the late 1800's and the early 1900's, whereby the employer was held liable for any accidents caused in the workplace regardless of fault. Contrary to common sense, this piece of legislation was not passed to aid workers but mainly to "assist employers rebut claims for damage" (Wilkinson 2001, 128) and "keep potentially costly and lengthy disputes out of the courts" (Chaklader 1998, 14). This Act was not comprehensive, not concise, left open wide areas of interpretation, and didn't stop workers going to courts and become more militant. Neither workers nor employers were satisfied with it. After lengthy disputes, commissions, strikes, and a generally messy situation, things evolved toward the compulsory insurance fund that exists today. WCBs were born under this insurance fund mechanism first introduced in industrialized nations and then taken as a model for many other nations. Although not all countries followed a rigid insurance mechanism (as the United Kingdom) agencies of the sort are prevalent in the United States, Canada, South America, and many other parts of the world. Both public and private WCBs were created and given authority regarding procedures and operation in the management of the workplace insurance fund. Whereas in Canada the insurance fund is managed through a public monopoly board in each province, in the United States, public monopoly boards exist in only six states and the others have a combination of public and private insurance agencies, or just private ones (Gunderson and Hyatt 2000). In developing countries with a weak state apparatus such as Chile, existing private WCBs were given permission to operate nationwide along with the public WCB (Dümmer 1997). In general, a combination of public/private WCBs exists today in many countries to prevent and compensate work-related injuries, diseases and deaths.

At present, and with some minor differences, WCBs' services consist mainly of (a) sick pay, financial compensation and pensions, (b) full medical aid, (c) risk prevention aid, and (d) 
safety inspection. However, to understand this industry it is necessary to avoid the mechanical reasoning of seeing WCBs as providers of the aforementioned services. Following Mosco's (2009) ontological approach to analyze institutions as social processes rather than structures, I claim it is indispensable to address WCBs in terms of their economic process of exchange rather than their structural duties-i.e. providers of medical, prevention and financial aid. This constitutes a vital move towards the understanding of the business relationship between these agencies and their client companies. If this approach is taken, we can see that contrary to common sense WCBs are not institutions that trade medical and preventive services. WCBs comprise an information sector whose main product is information to mathematically and instrumentally measure health and safety events in exchange for a premium. Although WCBs do provide prevention programs and medical treatment to their client companies, they do not exchange these services for money. The economic process of exchange takes place at the level of information. In return for a premium, which is set on the basis of safety information-i.e. lost days, incapacity rate and fatality rate-WCBs provide a guarantee of compensation for labour injuries, diseases and deaths. This business is an insurance business based on safety information. WCBs charge a premium to corporations to compensate absent labour-time caused by injuries, diseases and fatalities. The amount to be paid is determined by the safety information produced by WCBs' tracking, monitoring and measuring of absent labour-time. The more the absent labour-time produced by corporations the higher the premium to be paid. This economic reasoning comes from Ludwig Teleky's idea of introducing a sliding tariff for premiums according to the frequency of accidents (Wilkinson 2001, 43). Under this rationale, economic incentives rather than safety and health requirements would result in a safer workplace.

As WCBs are insurance agencies, these agencies do not engage in productive labour i.e., the production of surplus-value for the capitalist (Marx 1990). They take possession of surplus-value by other means. As Harvey (2006) explains, surplus-value can be appropriated in different ways: as profit on productive capital, profit on merchant's capital, interest on money capital and rent. In this regard, WCBs appropriate surplus-value as rentiers, basically as a deduction of the profits of their client corporations and therefore a form of rent paid out of workers. This process of appropriation of surplus-value from workers is indirect since it is taken from corporations rather than workers themselves. As the landlords of absent labourtime, WCBs collect a rent-i.e. the premium-from corporations to give them access and the right to exploit, harm and make workers sick. It is important to note that rent can be realized by WBCs due to their exclusive right in tracking, monitoring and measuring of absent labourtime and transforming it into safety information to set the magnitude of the premium. As Harvey (2002) puts it, "All rent is based upon the monopoly power [...] by virtue of their exclusive control over some directly or indirectly tradable item [...]" (94). It is therefore their legal privilege in producing and exchanging safety information in return for a rent that makes WCBs the cartel of absent labour-time.

Now, someone could point out the lack of merit of analysing WCBs' appropriation of surplus-value since the majority of them are public agencies, and if private, many of them are non-profit organizations, like WCBs in Chile. In this respect I claim that the public/private and profit/non-profit labels are misleading. Beyond the question of whether WCBs are private/public or profit/non-profit, it is the matter of how and what interests institutions operate for that should be taken into account, as some scholars correctly acknowledge (Calabrese and Mihal 2014). As Garnham (2014) argues, extreme simplification must be set aside in order to analyze the operation of public and private sectors. Particularly in this case, the private/public dichotomy has to be avoided because the main difference between public and private WCBs is based on the approach they take to regulate labour health and safety. Whereas private WCBs lean mainly toward economic incentives that reward or punish employers on the basis of the frequency and severity of injuries, diseases and deaths, public WCBs lean to the promulgation of rules prescribing specific policies and practices by employers, which are enforced through safety inspections and monetary penalties. The Chilean system, with almost no safety regulations, standards, supervision and enforcement, is a paradigm of the private approach to regulation. There are no more than 32 general labour safety 
and health norms and 331 inspectors nationwide to supervise more than 433.000 companies (Comisión Asesora Presidencial para la Seguridad en el Trabajo 2010). On the other side, the Canadian system, with a plethora of regulations, which include general requirementse.g. safe use of chemicals, confined space entry procedures-industry specific requirements and activity specific requirements-e.g. blasting, diving-as well as procedures to inspect workplaces, issue orders and impose penalties, accurately represent the public approach to regulation. However, it is crucial to note that both approaches are aimed at regulations not to the process of exchange. In terms of their economic process of exchange, public and private WCBs are exactly the same. Both are insurance companies that trade safety information against a rent. Both systems operate structurally under a capitalist logic, that is, on exchange value principles, the appropriation of surplus-value as rentiers and above all, the commodification of information. Public and private WCBs' process of economic exchange is to track and transform absent labour-time into safety information to set the premium to be collected from corporations as a form of rent. Therefore, it is absolutely necessary to focus on the economic process of exchange of these agencies, which revolves around information rather than addressing them based on their mystifying labels (public/private) that are limited to regulatory issues.

\section{WCBs' Economic Context}

To understand the relevance of safety information within this industry it is not enough to address WCBs' economic process of exchange but the economic environment within which these agencies operate. Although is vital to recognize these agencies as insurance companies, it is also central to understand the characteristics of their business context. As we shall see, safety information is sensitive to the economic regime where it does manifest. Its behaviour depends to a great extent on its economic context more than the autonomy and will of WCBs. Echoing Murdock and Golding (1973) a broader economic perspective to understand the production and circulation of symbolic resources, and a deeper exploration on the interplay between WCBs and their economic environment will be addressed.

It is no mystery that WCBs operate within a capitalist mode of production. However, this is a fact that is rarely taken into account and even analyzed. This recognition implies that the business relationship between WCBs and their client companies includes a series of specificities that can be only made clear by the capitalist logic. First of all, it is important to note that under capitalism corporations are mainly driven by profit, accumulation of capital and competition (Marx 1990). In this economic context, safety information as an exchange value is under the pressure of corporations and WCBs who want to control the premium to their own economic advantage. If we consider that workers' compensation benefits paid can represent nearly $1 \%$ of gross domestic product of a nation (Thomason 2005), it is evident why capitalists are so interested in controlling the premium. In addition, if Harvey's (2014) 3\% compound rate of growth as a rate that permits capitalists to gain a positive rate of return on their capital is taken into account, then that $1 \%$ related to compensation benefits is not something trivial. Therefore, it is due to a capitalist environment that WCBs' production of safety information is highly influenced by the logic of money. On the one side, the production of safety information through which the premium is determined is under a high strain by companies who don't want to see an increase on the premium. Corporations can engage in claim management to hold back workers' claims through which the premium is set (Thomason 2005). On the other side, safety information is under pressure because WCBs want to exercise control over costs (mainly public WCBs) or/and because they do not want to lose clients due to a premium surge and want to be attractive to draw new clients (mainly private WCBs). Therefore, the capitalist mode of production makes of this industry an information-saver one, that is to say, an economy based on the reduction of absent labour-time. Both WCBs and their client companies are highly encouraged and rewarded to be absent labour-time-savers; the former with a bigger market share or/and reduced medical costs, and the latter with a minimal premium.

Second, this economic system places power and control on a system of economic exchange (Marx 1978a). As Garnham explained, "[...] capitalism is a mode of social organiza- 
tion characterized by the domination of an abstract system of exchange relations" (1979, 125). This abstract system of exchange imposes different positions for people to occupy and participate in relation to their location within the means of production, what Marx (1978b) coined as class. On the one hand we have the working class-i.e. the owners of labourpower and on the other the ruling class-i.e. the owners of capital and the means of production (Marx 1978b). Both classes reside on opposite poles within this abstract system of exchange. In the case of WCBs and their client corporations these acute social positions do replicate. WCBs produce safety information under class conflict. As a use value, safety information props up labour risk awareness among the working class and enables the delivery of preventive, medical and financial aid; as an exchange value, safety information sets the magnitude of the premium to be collected from the ruling class-i.e. employers/corporations. Now, since employers are regarded as the clients, there exists a tremendous pressure on the exchange value of safety information. WCBs, in their attempt to satisfy their clients-i.e. employers - focus their attention on safety information as an exchange value rather than a use value. This occurs because workers are not regarded as clients but as consumers of WCBs' medical, preventive and financial aid. As far as the clients are companies rather than workers, the production of safety information must obey corporate needs-i.e. exchange value. In addition, since corporations are the clients, they are in a position to exert great pressure on WCBs' production of safety information. For example, in the case of a competitive market like the one inhabited by Chilean WCBs, corporations can fire their WCB and hire a new one if they are not satisfied with safety information provided. This explains why Chilean WCBs package, advertise and market safety information in the marketplace in an attempt to enlarge their customer base.

Finally, under capitalism, WCBs are governed by the power of abstraction and exchange value. Just as the capitalist economy involves the victory of quantity over quality, where everything is reduced to money (McNally 2011), WCBs reduce health events to units of the same kind, numbers and money. Work-related injuries, diseases, disabilities and deaths are artificially abstracted and converted into numbers-i.e. injury rate, lost days, fatality rate and incapacity rate. Safety information takes a quantifiable form. By reducing quality to quantity, injuries, diseases and deaths are presented as something natural to the workplace, as a myth (Barthes 1957), as common sense or statements of fact. Nobody dares to challenge that accidents are a part of the worksite. The absence of conceptual clarity allows the capitalist tool of calculation to produce a true discourse of safety and health, namely that workrelated injuries and diseases are ordinary events that can be reduced in frequency and intensity. In addition, by establishing a quantitative equality between labour health events and the premium, the commodity nature of safety information can be realized allowing the economic exchange to take place. In this regard, WCBs produce a universalized mode of representation in which injuries/diseases/deaths are individuated, separated, and assigned in a system of equivalence to exchange them against the premium. It is under a numerical system of equivalences that labour health events can be turned into money. In a capitalist regime, where abstraction and exchange value dominate, safety regulations, standards, guidelines, supervision and enforcement, have weak to no influence at all. It is the value of abstraction and the principle of exchange value that impose their supremacy.

As seen, safety information is greatly influenced by WCBs' capitalist economic environment. The control over the production of safety information is not a prerogative of WCBs. It is strongly shaped by the dynamics of an economic system based on profit maximization, competition, class conflict, the power of abstraction and a quantitative organization. That is why the production and circulation of safety information can be better explained in structural terms rather than on lack of competition, market concentration, regulations and enforcement. It is through the examination of the dynamics between WCBs and their client corporations within a capitalist regime that safety information can be properly addressed. Now that the context has being properly set, the examination of safety information can be put forth. The lines that follow put the commodity form of safety information at the centre of analysis as some communication scholars strongly suggest when analyzing communication, information and culture (Garnham 1979; Mosco 2009; Smythe 1977). 


\section{The Commodity Form of Safety Information}

Safety information constitutes a particular kind of commodity. Although it shares a lot of similarities with regular commodities, it bears some special characteristics that make it very exceptional. Its uniqueness has to do mainly with the fact that it is an informational commodity consisting chiefly of congealed absent labour-time (ALT). Although this might sound extremely weird, it is a fact and constitutes the essence of safety information. But before going into this peculiarity let's begin with those elements that are common to every commodity. As a commodity, safety information complies with Marx's (1990) main traits, (a) it is an object outside us, (b) satisfies human wants, and (c) it is a material depository of exchange value. As an object outside us, safety information is a group of signs that take the form of numbers and mathematical symbols that can be written, typed, amended, deleted and circulated independently of human beings. As a human want, safety information satisfies the need of measuring labour risk in a company or industry. As a material depository of exchange value, safety information serves as a means to set the premium and carry out the economic exchange. Now, in regard to its peculiarity, safety information comprises mainly of frozen ALT. This congealed ALT consists of workers' inability to perform their job with the average degree of skill and intensity due to a work-related injury, disease or death. In this regard, contrary to Marx's (1990) analysis of commodities as congealed labour-time, safety information is naught but the opposite, congealed ALT. It is ALT rather than labour-time that turns the safety information commodity into a useful thing-i.e. a use value-and a value through which it can be exchanged. Thanks to its amount of congealed ALT this commodity serves as a metric of risk and a means to determine the premium to be paid. ALT constitutes the main substance of safety information's value as well as the mode of expression of value-i.e. exchange value.

\subsection{The Value and Exchange Value of Safety Information}

Marx (1990) largely explains that commodities, beside their physical appearance, are characterized by having an immaterial phantom like form. Every commodity expresses itself in the market place through a dual character. However, these two forms play a different role. The body form of a commodity satisfies use value whereas the phantom like form enables the process of exchange to take place. This phantom like form, coined as value, consists of the equivalent substance of commodities that allow them to be swapped by one another. Marx defined value as the amount of labour-time socially necessary to produce a commodity. As Marx put it, "What exclusively determines the magnitude of the value of any article is therefore the amount of labour socially necessary, or the labour-time socially necessary for its production" $(1990,129)$. It is the quantity of labour-time socially necessary for the production of a given commodity, which determines both the magnitude of value and the magnitude of exchange value.

In the case of safety information, the value is not comprised just by labour-time socially necessary for its production. The value of safety information consists mainly of ALT. This occurs because it is congealed ALT, workers' inability to perform their job with the average degree of skill and intensity due to a work-related injury, disease or death, that determines the premium and enables the exchange. ALT represented by the sum of a patient's treatment time (measured by lost days), the incapacity to perform the job as an average worker (measured by the incapacity rate), or the perpetually incapable of working due to death (measured by the fatality rate), constitutes to a great extent the phantom form of safety information through which it can be priced. ALT is the key element of this commodity through which the economic exchange can be quantified and performed. But what type of absent labour does ALT involves? ALT includes both abstract and concrete absent labour-time. The abstract portion comprises the historical ALT record of an industry. It is an average of all the ALT created in a particular industrial classification-e.g. forestry, mining, and building. The concrete 
portion consists of the effective ALT record of an individual corporation. So both abstract and concrete absent labour-time comprise the value of safety information ${ }^{1}$.

However, it must be noticed that, even though congealed ALT comprises the biggest portion of the value of safety information, it is not all of it. A considerable amount of labour-time is also needed to create safety information. Safety information needs the labour-time expended by WCBs' bureaucrats to exist, that is, the processes of collecting, registering, classifying and calculating ALT. Without the bureaucratic labour-time expended by WCBs safety information is not created. This is a unique contradiction. Unlike any other commodity, the value of safety information is characterized by the combination of two opposite substances: $A L T$ and expended labour-time. Only the bizarre marriage of ALT and labour-time can give birth to the safety information commodity. As we shall see later, this contradiction is one of the main dilemmas of this sector. But for now, it must be clear that, although a considerable amount of labour-time is needed, ALT comprises the majority of the value of this commodity. It is its raw material. Safety information comes into existence due to an amount of ALT produced by a work-related injury, illness or death.

In regard to the exchange value of safety information, its proportion comes directly from ALT not from WCBs bureaucrats' labour-time. It is the amount of workers' inability to perform their job due to an injury, disease or death that determines exchange value. This is another reason why $A L T$ rather than labour-time is dominant in this commodity. The proportion of exchange value of safety information derives directly from ALT. Now, if we take into account a moral perspective-a constitutive component of a political economic analysis (Mosco 2009) - we can see the depraved nature of this commodity. The proportion of exchange value is directly related to workers' suffering. It is workers' misery in the form of ALT that determines the magnitude of exchange value. For example, if in the period of a year a corporation has an average of 2 lost days per worker, the proportion to be collected by WCBs will be considerably higher than a company within the same industry that has an average of 0.5 lost days per worker. It varies directly on the quantity and severity of injuries and diseases - and of course fatalities, and inversely on the lack of them. In this respect, it can be seen that the exchange value of this commodity can be reduced to ALT, pure, and simple. Opposite to Marx's claim that "As exchange values, all commodities are merely definite quantities of congealed labour-time" $(1990,130)$, the exchange value of safety information is its opposite, plainly ALT, which in essence is human suffering produced by the pursuit of profit.

As in any commodity, the exchange value of safety information counts quantitatively. In this case, the exchange value of this commodity represents mainly the quantity of ALT embodied in it. Thus, when taken in certain proportions, the information of the types of injuries and diseases are equal in exchange value. During equal periods of time and equal industry, equivalent quantities of ALT will yield exactly the same exchange value. This means that, under equal ALT, the exchange value of the information of falls, cuts, electrical shocks, burns, strains, bruises and sprains are-rewording Marx (1990)-identical as two peas. Thus, when placed in value-relation the information of injuries and diseases are nothing but exchange value. And as exchange value, safety information differs just in quantity. In addition, the same as every commodity, where the exchange value is the necessary form of expression of value (Marx 1990), the premium is the form of expression of ALT. The premium is the form of appearance or the necessary representation of ALT. It also represents both the abstract and concrete portion of ALT. The abstract portion of ALT-i.e. the historical ALT record of an industry-takes the name of "base rate" whereas the concrete portion-i.e. the corporation's individual ALT record-takes the name of "experience rating". Therefore the "base rate" and the "experience rating" are nothing more than the abstract ALT and the concrete ALT respectively embodied in the premium.

\footnotetext{
${ }^{1}$ For a matter of simplification, in the lines that follow ALT will always entail both abstract and concrete labourtime unless it is specified.
} 


\subsection{The Commodification of Safety Information}

Safety information must pass along a process of production in order to become a commodity and be exchangeable. This process of production, the becoming of a commodity, is known as commodification, the transformation of use value into exchange value (Mosco 2009). It is due to this process of commodification that safety information becomes a commodity and allows WCBs to exchange it for the premium.

As explained in the previous section, the value of this commodity is made up of ALT as well as labour-time, ALT being the main component. However, when it comes to the commodification process, it is the labour-time portion of value, which plays the major contribution. This must sound odd, since it has been repeatedly stated that congealed ALT is the essence of this commodity. But to be clear, the fact that labour-time comprises the main part of the commodification process does not diminish the relevance of ALT altogether. Therefore, although expended labour-time explains to a large extent the commodification process, ALT persists as the main element in this chain of production because it (a) triggers the commodification process and (b) sets the magnitude of exchange value.

The commodification of safety information needs to begin with the creation of ALT caused by a tragic event. This commodity is a suffering dependant one, since for its existence it needs the suffering of workers. But it is not any kind of suffering but a specific one; suffering experienced due to labour-time. Thus, ALT can become safety information only if it is originated by expended labour-time. The formula is simple: ALT produced by labour-time. This is the second contradiction of this commodity. Safety information commodity requires the production of ALT by means of expended labour-time, that is, by its opposite. To have a broader perspective of the process of commodification let's go back to the first contradiction. The first contradiction states that safety information is created by the combination of ALT and labourtime expended by WCBs. But as stated now, ALT must also be created by labour-time, because if not it will not be counted as safety information. So summing up to the peculiar marriage of ALT and labour-time to give birth to safety information, it is added as a condition that ALT must arise due to labour-time. In addition to both contradictions, there is another condition for the production of this commodity. The production of ALT should be equal or greater than at least one day lost ${ }^{2}$. Less than that is not enough to produce safety information. So wrapping up, the commodification of safety information depends on the combination of workers' ALT and WCBs' labour-time, where ALT is the product of expended labour-time and consists of at least one day lost.

Let's now take a closer look to the process of commodification. As explained, it begins when a worker has an injury or disease that disables him from performing his job. When this occurs ALT is naturally created due to the inability of the worker to get back to work. When at least a unit of ALT-i.e. one day lost-is produced, WCBs enter the stage and appropriate workers' lack of labour-power. In this respect, WCBs' commodification process entails the appropriation by means of the collection, registration, classification and calculation of workers' ALT in order to turn it into something exchangeable. Without the act of appropriating workers' ALT this commodity is not produced. The appropriation takes place by transforming ALT into an object outside of us, specifically a group of signs that are expressed in the forms of numbers and rates-i.e. injury rate, lost days, incapacity rate and fatality rate. The commodification of safety information is above all a bureaucratic process that needs concrete material activities and practices to take place. The first step, the collection of ALT, requires of the injured/ill worker to arrive at an official medical facility to be assessed and treated. The worker generally performs this material activity, which of course comprises labour-time, by the employer or by a WCBs' ambulance service. Without the expenditure of this labour-time, workers' ALT is never collected and once workers' ALT is collected, the commodification circuit continues with WCBs' registering stage. This stage is extremely dependent on a series of medical practices performed on the basis of the severity of the accident or disease. Usually, the registration stage is done by clerical workers who expend labour-time accurately regis-

\footnotetext{
${ }^{2}$ Not every WCB counts injuries and diseases from the first day. Some WCBs - like Canadians - impose a waiting period of 3 days. Therefore this number depends on each WCB's norms and procedures.
} 
tering the date of entry and exit of the injured/ill worker in order to precisely measure the number of lost days. Also, the registration stage includes the recording of basic information such as name, gender, age, company, economic sector, type of event, diagnosis, etc. This labelling allows WCBs to identify which client companies the ALT is coming from and to record the concrete ALT-i.e. the sum of the effective ALT of an individual corporation, which serves to set the 'experience rating' section of the premium. The registration stage gathers an amount of information related to ALT, which is vital for the steps that follow. The classification stage that comes next mainly consists of the practice of grouping all the information that comprises ALT along industry and size of the company. Although it is usually carried out by information and communication technologies, it does comprise labour-time. The classification of ALT information along industry and size is vital to set the magnitude of exchange value in the next step. Particularly, it is done in order to obtain the abstract portion of ALT, that is, the average of all the ALT created in a particular industry, which allows establishing the "base rate" section of the premium. Finally, the calculation phase, carried out entirely by information and communication technologies, is the step that makes safety information a depository of exchange value. This stage calculates the required components of ALT against the clients company's industry "base rate", "experience rating", number of employees, average wages, and comes up with the magnitude of exchange value. This calculation process is a complex mathematical procedure that includes the quantification of the data previously registered and classified. It is through this last phase that safety information finally becomes a commodity, a material object depository of exchange value. Now, it is interesting to note that it is workers' ALT, which is appropriated, objectified and quantified in order to be exchanged. In this regard, similar to Marx's analysis, this commodity is also the result of workers' exploitation. But in this case it is not the exploitation of workers' labour-power, but rather the exploitation of workers' lack of labour-power. WCBs exploit the lack of labour-power to commodify safety information and exchange it. As seen, the commodification of safety information is a long and complex process that begins with the creation of at least a unit of ALT due to expended labour-time, and ends with an object outside of us which is the depository of exchange value through which a premium can be set and charged.

Beyond exchanging safety information against a premium, what WCBs do once the safety information is commodified depends on WCBs public/private nature. In this regard, private WCBs take a very aggressive commercial approach that is interesting to address. Mainly they engage in promoting, advertising, marketing and commercializing safety information to draw new client corporations. In order to perform these traditional commercial practices, WCBs perform client segmentation in an attempt to exercise effective and efficient control over the safety information and its commercialization. Private WCBs normalize and reinforce patterns of size and segregation to effectively commercialize safety information. Rather than organizing companies according to health and safety needs, these agencies arrange and classify client companies according to the revenue generated by the exchange value - i.e., the premium. Since WCBs' income source depends mainly on the size of companies in terms of workers, segmentation takes place mainly through patterns of size. Big companies are provided with direct contact-exclusive executive_as well as "free lunch" (Smythe 1977), a bunch of safety merchandising, safety programs, safety products and services. Small companies are given just the minimum: basic safety guidelines and a password to operate through the internet. These sharp distinctions between big and small companies do not reflect real differences or safety needs; they assist in classification, organization and identification of clients for commercial purposes. In addition, very similar to Smythe's (2012) concept of predictable specifications, the commercialization of safety information falls in economic sector classes-e.g. fishery, forestry, building, utilities, mining-enabling the modelling of safety demand to fit the needs of big corporations. Finally, in the aim to control the consumer's market, private WCBs try to build a market monopoly using advertising to create brand identification. These agencies engage in advertising favourable to corporate interests in order to build their brand around a pro-corporate appeal and imbue themselves with an attractive business image. On a regular basis WCBs advertise their low rates through the mass media and what they call a "safety culture", a series of hegemonic messages directed to the 
general public on how to achieve health and safety at the worksite. These messages tend to reinforce both the displacement of accidents' responsibility, from the organization to workers, and the economic perspective of safety.

\subsection{The Fetishism of Safety Information}

Marx's (1990) concept of fetishism signals how important things about the production of commodities get concealed because of its internal contradictions. As Harvey (2010) explains, fetishism is mainly the result of the contradiction between the use value and value of a commodity. "Our sensuous experience with the commodity as a use-value has nothing to do with its value" (Harvey 2010, 39). Regarding safety information, this account is also true. There is no relationship between safety information as a use value-i.e. a group of numbers and rates that measure labour risk-and as a value-i.e. both labour-time and ALT. In fact, the main problem is that the labour-time section of this commodity is concealed. It is not recognized that the value of safety information implies a considerable amount of labour-time to collect, register, classify and calculate ALT. This occurs because safety information as numbers and rates don't reflect the labour-time needed for its production but just the ALT portion. It is not possible to know the real value of this commodity. Thus, as any ordinary commodity, safety information represents itself as a reflection of reality and conceals the secret of its process of production. As a group of numbers and rates outside of us safety information appears as a measure of labour risk. But it is just a form of appearance. Safety information as a commodity successfully hides the distortions, which derive from its process of production due to the labour-time expended. As we shall see in the lines that follow, the routine practices of WCBs and companies to alter safety information at the stages of data collection, registration, organization, conceptualization, classification and calculation, are completely obscured and hidden from the public gaze. The fetishism quality of safety information keeps these alterations away from citizens' consciousness. The social relations that take place to produce this commodity are hidden. Safety rates are reified and take life on their own as an accurate representation of labour risks at the worksite.

In addition, fetishized safety information not only conceals its process of production and the distortions that occur but the struggle between corporate and workers interests. Fetishized safety information prevent workers from realizing that distortions operate to the benefit of WCBs, companies and the state, to the detriment of their own health and safety. Due to the upholding of rates exerted by WCBs and companies, the former to keep their market share or operational costs at bay, and the latter to keep their contribution from surging, workers are restricted and deprived from the medical and financial benefits they are entitled to. In addition, distorted injury rates, lost days and incapacity rates misguide both workers and citizens on health and safety matters. Thanks to this fetishized commodity the capitalist worksite is presented as harmless. The ideology of the "safe workplace" is begotten. Safety information covers up the fact that the capitalist mode of production not only produces a deterioration of workers but also the early exhaustion and death of workers. As Marx clearly put it, "It [capital] attains its objective by shortening the life of labour-power [...]" $(1990,376)$. Therefore, it is in fact the conflict between capital and workers' health and safety that is ultimately blurred and concealed.

\section{The Power of Safety Information}

Since WCBs' process of economic exchange is organized through the commodification of safety information, all actors place their focus primarily on safety information rather than any other feature-e.g. quality of medical services, comprehensiveness of preventive strategies, emergency infrastructure. Both WCBs and client companies organize themselves around safety information in order to manage labour health and safety. In this respect, the power of safety information as an articulator of this industry derives naturally from the capitalist economic regime within which WCBs operate (as stated previously), and particularly from two factors; (a) the contradictory relationship between its use and exchange value and the dominance of the latter, and (b) the curious marriage of ALT and labour-time to give birth to this 
commodity. These two traits allow safety information to take an active role in producing and organizing social life rather than being a reflection of it.

As Harvey (2014) points out, the use value and exchange value of commodities have a contradictory relationship. Under certain circumstances the use value and exchange value of a commodity tend to not come together but rather disagree, diverge or get annulled by the other. In this case, the use value of safety information-i.e. the measure of labour risk-is eaten up by its exchange value-i.e. the function of serving as a means to set the premium and carry out the exchange. This occurs mainly because the exchange value of safety information is a means of carrying out a purpose unconnected with the production of use value. Since safety information is produced by WCBs, and acquired by companies for what it can bring in exchange, the use value of safety information gets distorted by the economic need of WCBs and their client companies to shape exchange value-i.e. the magnitude of the premium-to their advantage. Both WCBs and their client companies are economically stimulated to intervene in reality in an attempt to diminish the quantity of ALT in their own favour. For example, companies tend to misinform, discourage, obstruct and even threaten workers to prevent them from reporting injuries and diseases (Zoller 2003; Frederick and Lessin 2000). Also, companies avoid reporting accidents through official channels through the practice of delivering injured workers to non-official health institutions and registering them as common accidents rather than work-related ones (Zoller 2003). In addition, by engaging in claim management-i.e. actions to block workers' legitimate claims-corporations reduce injury reports (Thomason 2005). These simple manoeuvres enable companies to block the collection and registering stages on which the production of safety information depends, with the objective of holding the premium back. Although WCBs are well aware of these manoeuvres, they tend to ignore them, on the one side, to avoid disputes and keep intact their market share, and on the other, to reduce medical and financial costs. Nevertheless, WCBs do not take only a passive and lenient position to prevent the rise of ALT. They also place pressure on some stages of the process that are under their influence to uphold ALT for keeping corporations happy. Under the guise of efficiency WCBs engage in the practice of "express medical services"-i.e. quick medical assistance-to minimize ALT and prevent their client companies from a higher premium (Finkelstein 2009). This practice is usually justified by WCBs' rationale of returning workers back to the labour force as quickly as possible, which makes it very difficult to condemn it. In addition, WCBs have more sophisticated ways of decreasing ALT like redefining concepts and increasing the standards to be met for accepting workers' claims. By limiting how disability is defined and measured, a wide range of disabilities are excluded from coverage and compensation, thus allowing WCBs to achieve cost savings (Guenther, Patterson and O'Leary 2009). ALT produced by chronic pain, Post-Traumatic Stress Disorder, depression, anxiety, and other psychological injuries, is successfully halted. Also, WCBs take indirect bureaucratic measures in order to decrease ALT and hold back the premium. For example, obstructing and slowing workers' claim by making decision-making excessively technical and narrow or making the appeal process difficult to understand and inaccessible (Guenther, Patterson and O'Leary 2009). WCBs' bureaucracy can easily translate into fewer claims. And fewer claims translate into lower premiums (Frederick and Lessin 2000). These administrative procedures are extremely difficult to denounce since they are strictly executed under the reign of the law. However, it is easy to see that they are focussed on cost reduction for employers rather than expanding the coverage and benefits for workers. These few examples illustrate how the primacy of the exchange value over the use value of the safety information commodity stimulate WCBs and their client companies to engage in undesirable practices to keep ALT from raising, hence unintentionally preventing the safety information commodity to truthfully reflect labour hazards-i.e. its use value. It is the contradictory relationship between the use and exchange value of safety information, and the primacy of the latter, which explains the power of this commodity in producing and shaping reality.

Now, how can WCBs and corporations so easily manipulate ALT? Just by altering the labour-time portion of this commodity. In this respect, it is the twofold and contradictory character of the process of commodification that opens a huge gap for the manipulation to take 
place. As this commodity needs both ALT as well as labour-time to come into existence, WCBs and corporations can put into practice subtle manoeuvres to alter the ALT portion by intervening in the labour-time section. They do not need to prevent work-related injuries and diseases from happening to diminish ALT, but rather to intervene in the labour-time section of this commodity to modify the magnitude of exchange value. To be clear, it is the labourtime portion of this commodity, that is, the collection, registration, classification and calculation of ALT that is targeted by WCBs and corporations. If it were not for the fact that an important amount of labour-time is expended in the production of the safety information commodity, there would not be any fissure to alter the amount of ALT so effortlessly. In consequence, the ability of safety information to recruit WCBs and corporations in preventing, blocking, delaying or speeding up some of the stages of the process of commodification to alter the magnitude of ALT, is given by the dual and contradictory character of this process.

\section{Concluding Remarks}

Safety information looks different when the starting point is political economy. Disclosed as an informational commodity in a business relationship, safety information plays an active role in producing and organizing social life instead of mirroring it. In fact, it is the labour health and safety that reflects the internal contradictions of the safety information commodity rather than the other way round. Both WCBs and corporations are pushed into dishonest activities due to the safety information commodity's (a) exchange value supremacy and (b) twofold and contradictory process of commodification. It is through the architecture of the safety information commodity that concrete events take place in this industry. Health and safety practices are subordinated to this commodity's internal structure.

However, the muscle of the safety information commodity depends largely on the economic environment where it manifests. Being context dependent, it is under a capitalist mode of production that the safety information commodity can rule with no counterpart. Since it unfolds in an economic system based on profit maximization, competition, class conflict, the power of abstraction and a quantitative regime, the power of WCBs to control safety information is insignificant. That is why even public WCBs which try to regulate labour health and safety through rules, standards, supervision and enforcement can do so little to exert control over safety information. Forcing the safety information commodity to be accurate and express use value-i.e. a measurement of labour risk-is not possible in a capitalist environment. Thus, the temptation to resolve this matter through the promulgation of rules prescribing policies should be restrained. This is an issue that has to be addressed by dealing with the economic base of WCBs. The production of accurate safety information in accordance with workers' and citizens' non-commercial needs can be achieved only by intervening on WCB's economic process of exchange and its economic context.

To end, I want to point out that this analysis discloses a troubling conclusion, one that defies, in some respect, Marx's theory of value. Under his theory, value is defined as the amount of labour-time socially necessary to produce a commodity (Marx 1990). He stated that commodities are "congealed labour-time". However, this analysis demonstrates that commodities are not just labour-time but also the opposite, ALT. If we take into account that under WCBs' compulsory insurance fund mechanism every worker must produce enough value to pay the premium, then we can recognize that ALT is embedded in every commodity. This occurs because the premium, the money form deduced from corporations and paid out of workers to cover the insurance fund, is not only comprised by labour-time but also from $A L T$. It is a necessary condition for the premium to carry ALT, workers' inability to perform their job with the average degree of skill and intensity due to a work related injury, disease or death. In fact, it is the quantity of concrete and abstract ALT that determines the magnitude of the premium. On the one hand, the abstract portion, that is, the average ALT of a particular industry, determines the "base rate" of the premium. On the other hand, the concrete portion, that is, the sum of the effective ALT of an individual corporation, determines the "experience rating" of the premium. The premium is nothing more than abstract and concrete ALT. Consequently, since workers have to produce enough value to pay the premium, which is an 
equivalent of the sum of abstract and concrete ALT, then the creation of every commodity necessarily includes a certain amount of ALT due to injuries, diseases and deaths. By buying a pair of shoes one is not only paying for the labour-time expended by workers in producing this commodity but for the historical average of ALT of the shoes' industry as well as the effective ALT of the individual shoes' company. Commodities do not comprise only of necessary labour-time but also of necessary ALT, concrete and abstract human suffering that is quantified and valorised by WCBs' monopoly in tracking, monitoring and measuring of ALT. In this respect, it can be said that workers add value by congealing necessary labour-time as well as necessary ALT into commodities. Through injuries, diseases and deaths, workers transfer to the premium the value they themselves lose during the labour process by the destruction of their own use-value. Workers' use-value-i.e. labour-power-uure-appears in the value of every commodity as the premium. The production of ALT by workers is then a form of labour. Now, just as labour-time that cannot be recognized but through its exchange against money (Marx 1990), ALT cannot be recognized but through its exchange against the premium. The premium is the necessary materialization of abstract and concrete necessary ALT. So there it is. Commodities are both congealed necessary labour-time and congealed necessary ALT, where ALT takes the appearance of the premium against which the rent can be set and collected by WCBs.

\section{References}

Barthes, Roland. 1957. Mythologies. New York: Hill and Wang.

Calabrese, Andrew and Colleen Mihal. 2014. Liberal Fictions: The Public-Private Dichotomy in Media Policy. In The Handbook of Political Economy of Communications, edited by Janet Wasko, Graham Murdock and Helena Sousa, 226-263. Oxford: John Wiley.

Chakadler, Anjan. 1998. History of Workers' Compensation in BC. Report to the Royal Commission on Workers' Compensation in BC. BC: Canada.

Comisión Asesora Presidencial para la Seguridad en el Trabajo. 2010. Informe final. Accessed March 10, 2013. http://www.comisionseguridadeneltrabajo.cl.

Dümmer, Walter. 1997. Occupational Health and Workman's Compensation in Chile, Applied Occupational and Environmental Hygiene 12 (12): 805-812.

Finkelstein, Rodrigo. 2009. El Rol Constitutivo de la Seguridad Ocupacional. Ciencia\&Trabajo 33 (11): $145-151$.

Frederick, James, and Nancy Lessin. 2000. Blame the Worker: The Rise of Behavioral-Based Safety Programs. Multinational Monitor 21 (11): 10-17.

Garnham, Nicholas. 1979. Contribution to a Political Economy of Mass Communication. Media, Culture \& Society 1 (2): 122-146.

Garnham, Nicholas. 2014. The Political Economy of Communication Revisited. In The Handbook of Political Economy of Communications, edited by Janet Wasko, Graham Murdock and Helena Sousa, 41-61. Oxford: John Wiley.

Guenther, Stan, Janet Patterson and Sarah O'Leary. 2009. Insult to injury: Changes to the BC Workers' Compensation System (2002-2008). Report to the BC Federation of Labour. BC: Canada.

Gunderson, Morley, and Douglas Hyatt. 2000. Foundations for Workers' Compensation Reform: Overview and Summary. In Workers' Compensation: Foundations for Reform. Toronto: University of Toronto Press.

Harvey, David. 2002. The Art of Rent: Globalization, Monopoly and the Commodification of Culture. Socialist Register 38: 93-110.

Harvey, David. 2006. The Limits to Capital. London: Verso

Harvey, David. 2010. A Companion to Marx's Capital. London: Verso.

Harvey, David. 2014. Seventeen Contradictions and the End of Capitalism. New York: Oxford University Press.

Marx, Karl. 1978a. The German Ideology: Part I. In The Marx-Engels Reader, 2nd ed., edited by Robert C. Tucker, 146-200. New York: W. W. Norton \& Company.

Marx, Karl. 1978b. Capital, Volume 3. In The Marx-Engels Reader, 2nd ed., edited by Robert C. Tucker, 439-442. New York: W. W. Norton \& Company.

Marx, Karl. 1990. Capital: Volume I. London: Penguin Classics.

McNally, David. 2011. Global Slump: The Economics and Politics of Crisis and Resistance. Winnipeg: Fernwood Press.

Mosco, Vincent. 2009. The Political Economy of Communication, 2nd ed. London: Sage. 
Murdock, Graham and Peter Golding. 1973. For a Political Economy of Mass Communications. In The Socialist Register 1973, edited by R. Miliband and J. Saville. London: The Merlin Press.

Smythe, Dallas. 1977. Communications: Blindspot of Western Marxism, Canadian Journal of Political and Social Theory 1 (3): 1-27.

Smythe, Dallas. 2012. On the Audience Commodity and its Work. In Media and Cultural Studies: Key works, edited by Meenakshi Durham and Douglas Kellner, 185-204. West Sussex, UK: WileyBlackwell.

Thomason, Terry. 2005. Economic Incentives and Workplace Safety. In Workplace Injuries and Diseases: Prevention and Compensation Essays in Honor of Terry Thomason, edited by Karen Roberts, John F. Burton, and Matthew M. Bodah. Michigan: W. E. Upjohn Institute for Employment Research.

Wilkinson, Carol. 2001. Fundamentals of Health at Work: The Social Dimensions. London: Taylor \& Francis.

Zoller, Heather. 2003. Health on the Line: Identity and Disciplinary Control in Employee Occupational Health and Safety Discourse, Journal of Applied Communication Research 13 (2): 118-139.

\section{About the Author}

Rodrigo Finkelstein

Rodrigo Finkelstein is a PhD student in the School of Communication at Simon Fraser University. His research interests include the political economy of safety information, discourse of occupational health and safety, and Marxist theory of Workers' Compensation Board. 